\title{
Os limites da igualdade de oportunidade $^{1}$
}

François Dubet

Sociólogo, professor da Resumo: Nas últimas décadas, a “igualdade de Universidade de Bordeaux II. oportunidades" foi-se impondo sobre outra visão de É autor, dentre outros livros, matriz sociodemocrata que o autor denomina "igualdade de Repensarlajusticiasocial. de posições". Aqueles que defendem a igualdade de Contra el mito de igualdad oportunidades - o modelo norte-americano - preocupamde oportunidades (Siglo XXI: $\quad$ se menos em reduzir as desigualdades do que lutar contra Buenos Aires, 2011). as discriminações que impedem transitar pela estrutura social em função de méritos pessoais. 0 artigo sustenta que a esquerda deve combinar igualdade de posições com igualdade de oportunidades, mas dando prioridade à primeira, o que não deve se confundir com uma defesa conservadora do Estado de Bem-estar tal como hoje o conhecemos.

Palavras-chave: Igualdade de oportunidades. Igualdade de posições. Meritocracia. Estado de Bem-estar.

Publicado originalmente em espanhol, em "Nueva Sociedad”, Buenos Aires, n. 239, mayo-junio de 2012. p. 42 50. Disponível em www.nuso.org. Trad. do francês de Aldo Giacometti. Tradução para o português de Antônio A. G. Batista. Cadernos Cenpec agradecem a Nueva Sociedad e François Dubet pela autorização da tradução. Agradecem ainda a François Dubet pelo acesso ao original em francês. 
Duas grandes concepções de justiça social se combinam, se justapõem e se enfrentam hoje em dia, ainda que sua definição e as tensões que as opõem estejam frequentemente dissimuladas pela generosidade dos princípios que as inspiram e pela imprecisão do vocabulário que as sustenta. Essas duas concepções de justiça social procedem de um problema comum: buscam reduzir a tensão fundamental das sociedades democráticas entre a afirmação da igualdade fundamental de todos os indivíduos, por um lado, e as desigualdades reais vinculadas às tradições, à competição entre interesses e ao "normal" funcionamento das sociedades modernas, por outro. Essas duas grandes soluções são a igualdade de posições e a igualdade de oportunidades. Em ambos os casos, se trata de reduzir certas desigualdades sociais com o propósito de torná-las aceitáveis, se não perfeitamente justas, na sociedade em que vivemos.

Sem dúvida, cada uma dessas maneiras de concebera justiça social é excelente: há grandes probabilidades que desejemos viver em uma sociedade que seja, ao mesmo tempo, relativamente igualitária e relativamente meritocrática. Nós ficamos igualmente escandalizados pelas diferenças de renda que separam os mais pobres e os que ganham anualmente várias dezenas de salários mínimos, pelas discriminações impostas às minorias, às mulheres e aos diversos grupos segregados que não podem mudar de posição porque eles estão como que designados a "seu” lugar. À primeira vista, não se trataria de escolher entre o modelo de posições e o de oportunidades, já que, depois de John Rawls e de muitos outros pensadores antes dele, sabemos que sociedade democrática verdadeiramente justa deve combinar a igualdade fundamental de todos os seus membros com as "desigualdades justas" que surgem de uma competência meritocrática equitativa. Sabe-se que essa alquimia está no coração de uma filosofia política democrática e liberal que garanta a cada um o direito de levar sua vida tal como entende, no marco de uma lei e de um "contrato" comuns. 


\section{A IGUALDADE DE POSIÇÕES}

A primeira dessas maneiras de conceber a justiça social se centra nas posições que organizam a estrutura social, quer dizer, no conjunto dos lugares ocupados pelos indivíduos, sejam mulheres ou homens, membros de minorias visíveis ou da maioria "branca”, "cultos” ou menos "cultos", jovens ou menos jovens... Essa representação da justiça social convida a reduzir as desigualdades de renda, de condições de vida, de acesso a serviços, de segurança... que estão associadas às posições sociais ocupadas por indivíduos muito distintos em vários aspectos: as qualificações, o sexo, a idade, o talento. A igualdade de posições busca reduzir a distância entre essas posições sociais e não privilegiar a circulação dos indivíduos entre os diversos postos desiguais.

Neste caso, a mobilidade social é uma consequência indireta da relativa igualdade social. Em poucas palavras, trata-se menos de prometer aos filhos de operários que eles terão as mesmas chances que os filhos de executivos de se tornarem também executivos do que reduzir a distância existente entre as condições de vida e de trabalho entre os operários e os executivos. Tratase menos de permitir que as mulheres ocupem os mesmos tipos de empregos hoje reservados aos homens do que fazer com que os empregos ocupados pelas mulheres e pelos homens sejam mais equivalentes em termos de remuneração ou de outras condições.

A igualdade de posições foi colocada pelo movimento operário e, mais amplamente, pela esquerda. Durante mais de um século, ela buscou reduzir as desigualdades entre as posições sociais por meio da segurança social contra os imprevistos da vida e os riscos da economia, por meio da redistribuição da riqueza, mediante as contribuições sociais e um imposto progressivo sobre a renda, bem como por meio do desenvolvimento dos serviços públicos e do Estado de bem-estar social. Segundo essa perspectiva, as desigualdades sociais são reduzidas, em primeiro lugar, no terreno das condições de trabalho e dos salários onde se constituem. Os países que desenvolveram essas políticas são muito menos desiguais que os outros. Trata-se de um modelo de justiça social que constrói uma representação da sociedade em termos de classes sociais e que indexa as desigualdades à esfera do trabalho. Mais que isso, a igualdade de posições constrói um contrato social expandido e uma solidariedade essencialmente "cega" às "dívidas", aos "créditos" e às responsabilidades de cada indivíduo.

Esse modelo de justiça, contudo, enfrenta hoje numerosas críticas. Critica- 
se, entre outras coisas, ter desenvolvido um Estado corporativista em que cada um defende sua posição e as vantagens adquiridas. Nesse sentido, seria pouco eficiente, e a crítica liberal não deixa de sublinhar as altas taxas de desemprego dos Estados de bem-estar corporativistas. Também se critica o enfraquecimento da confiança e da coesão sociais, já que cada indivíduo depende mais do Estado do que seus concidadãos. Assim, a igualdade de posições seria com frequência conservadora. Cega a discriminações que sofrem sobretudo as mulheres e os operários, a igualdade de posições privilegiaria os homens brancos e qualificados; ela convidaria cada um a continuar em seu lugar, em vez de buscar a mudança de posição. Enfim, de acordo com tais críticas a igualdade de posições seria cada vez mais indefensável num mundo globalizado no qual os sistemas de proteção social competem entre si.

\section{A IGUALDADE DE OPORTUNIDADES}

A segunda concepção de justiça, aquela que progressivamente se impõe hoje em dia, é centrada na igualdade de oportunidades ofertada a todos para ocupar quaisquer posições, baseada no princípio meritocrático. Ela objetiva menos reduzir as desigualdades das posições sociais que lutar contra as discriminações que constituem obstáculos à realização do mérito, permitindo a cada um ter acesso a posições desiguais ao final de uma competição equitativa na qual indivíduos iguais se enfrentam para ocupar lugares sociais hierarquizados. Nesse caso, as desigualdades são justas, uma vez que todos os lugares estão abertos para todos. No caso da igualdade de oportunidades, a definição das desigualdades sociais muda sensivelmente em relação ao modelo das posições. As desigualdades sociais são tidas menos como desigualdades de posições e mais como um conjunto de obstáculos que se opõem ao estabelecimento de uma competição equitativa. Nesse modelo, a estrutura de posições não é discutida a priori. 0 ideal não é uma sociedade na qual as desigualdades de posições sejam limitadas; o ideal é uma sociedade na qual cada geração deveria ser redistribuída equitativamente em todas as posições sociais em função dos projetos e dos méritos dos indivíduos. Nesse segundo modelo, a justiça requer que os filhos dos operários tenham as mesmas oportunidades que os filhos de executivos de modo que ambos possam, por sua vez, serem executivos, sem que a distância de posição entre operários e executivos esteja em jogo. 0 modelo das oportunidades implica que as mulheres tenham presença paritária em todos os escalões da sociedade, sem que a escala mesma das atividades profissionais e da renda seja transformada. Essa imagem da justiça social também obriga a considerar 
o que se conhece como "diversidade" étnica e cultural, com o objetivo de que esteja representada em todos os níveis da vida social.

A igualdade de oportunidades muda profundamente as representações da sociedade. As classes sociais são substituídas por grupos que passam a ser definidos com base nas discriminações que sofrem em razão de sua "raça", de sua cultura, de seu sexo e de seus "handcaps"2. Como esses estigmas são negativos, cada um dos atores que denuncia as discriminações afirma simultaneamente uma exigência de reconhecimento que transforma assim o estigma em características positivas, traços culturais e sociais que fundam a diversidade da sociedade. A representação da sociedade também muda completamente quando as minorias substituem as classes sociais. As associações, as fundações, as diversas agências de luta contra as discriminações tomam progressivamente o lugar dos sindicatos, reclamando cotas e levando diante da justiça a luta contra as discriminações. Isso desestabiliza profundamente os modos de representação política. 0 contrato social "cego" é substituído por contratos mais individualizados, que comprometem a responsabilidade de cada indivíduo e os levam a fazer valer seu mérito para otimizar suas oportunidades. Se ele triunfa, melhor para ele; se fracassa, pior para ele.

Esse modelo de justiça pode ser criticado por razões opostas às que são apresentadas contra o modelo de igualdade de posições. Em primeiro lugar, não parece que a igualdade de oportunidades reduza as desigualdades sociais; os países que aplicam esse princípio de justiça social (principalmente Estados Unidos e Grã-Bretanha) exibem maior desigualdade que os países socialdemocratasecorporativistas. Éverdadequeaigualdadedeoportunidades não nos diz que desigualdades são intoleráveis e se limita a oferecer uma rede de salva-vidas para os mais pobres. A definição das injustiças em termos de discriminação gera um mecanismo de competição entre as vítimas que estão interessadas em "exibir" suas discriminações para beneficiar-se de políticas específicas. No final das contas, a miríade das minorias substitui a miríade das corporações. Enfim, não é seguro que a igualdade de oportunidades seja mais liberal, mais favorável à autonomia que a igualdade das posições. Substitui o conservadorismo dos lugares sociais pelos rigores do mérito, já que cada um é tido como plenamente responsável pelo que lhe ocorre. Assim, os governos que privilegiam a igualdade de oportunidades são com frequência os mais conservadores, os mais dados a "culpar as vítimas", na medida em que elas não souberam aproveitar suas oportunidades.

2 Em inglês, no original. [n. do trad. bras.] 


\section{PRIORIDADE À IGUALDADE DE POSIÇÕES}

O fato, porém, de que queremos ao mesmo tempo a igualdade de posições e a igualdade de oportunidades não nos dispensa de escolher a ordem de nossas prioridades. Com efeito, em termos práticos, em termos de políticas sociais e de programas políticos, não se faz exatamente o mesmo se se escolhe primeiro as posições ou as oportunidades. Por exemplo, não é igual afirmar como prioridade o aumento dos salários baixos e a melhoria das condições de vida dos bairros populares ou escolher como prioritária a necessidade imperiosa de fazer com que as crianças desses bairros tenham as mesmas oportunidades que outras de aceder à elite em função de seu mérito para escapar de sua condição. Eu posso optar por abolir a posição social injusta ou então por permitir aos indivíduos sair dessa posição, sem colocar em causa as condições mesmas. E se desejo fazer as duas coisas, é necessário escolher bem o que faço primeiro. Em uma sociedade rica, mas necessariamente obrigada a estabelecer prioridades, não é o mesmo escolher melhorar a qualidade da oferta escolar nos bairros desfavorecidos ou ajudar aos que têm maior mérito entre os alunos desfavorecidos a fim de que tenham a oportunidade de unir-se à elite escolar e social. Para escolher um exemplo mais claro, não é o mesmo fazer com que os membros das minorias étnicoraciais estejam representados de maneira equitativa no Parlamento e na mídia que fazer com que os postos que ocupam na construção civil e nos serviços de manutenção dos prédios públicos tenham melhores recompensas e sejam menos penosos. 0 argumento segundo o qual, idealmente, tudo deveria ser feito não resiste aos imperativos da ação política, que tem que escolher fatalmente o que parece ser mais importante e mais decisivo. Podemos desejar tanto a igualdade posições quanto a igualdade de oportunidades, mas se não queremos viver de ilusões, estamos constrangidos a escolher o caminho que pareça mais justo e mais eficaz, estamos obrigados a dar prioridade a um dessas duas concepções de justiça.

A opção se impõe ainda mais quando se leva em conta que esses dois modelos de justiça social não são somente esquemas teóricos discutíveis, tanto um como o outro. Na verdade, estão sustentados por movimentos sociais diferentes, que privilegiam grupos e interesses também distintos. Esses modelos não mobilizam nem constroem exatamente os mesmos atores nem os mesmos interesses. Eu não me defino nem atuo da mesma maneira se luto para melhorar minha posição ou se me bato para aumentar minhas oportunidades de sair de minha posição. No primeiro caso, o ator geralmente é definido por seu trabalho, por sua “função", por sua “utilidade” e por sua 
exploração... No segundo caso, ele é definido por sua identidade, por sua "natureza" e pelas discriminações que sofre como mulher, como minoria estigmatizada... Sem dúvida, ambas as maneiras de definir-se, de mobilizar-se e de atuar no espaço público são legítimas, mas não podem ser confundidas e, aí também, nos toca escolher qual das duas deve ser prioritária. Não é necessário reificar as classes sociais, por um lado, ou as “minorias", por outro, para compreender que uma sociedade não se percebe nem atua sobre si da mesma maneira se prioriza as posições ou as oportunidades.

Se defendo a prioridade da igualdade de posições, não é então para negar a legitimidade à justiça das oportunidades e do mérito, mas por duas razões essenciais.

A primeira é que a igualdade, ao convidar a um ajuste da estrutura social, é "boa” para os indivíduos e sua autonomia; aumenta a confiança e a coesão social na medida em que os atores não se engajam numa competição contínua, aquela que consiste em ter sucesso e aquela que consiste em expor seu estatuto de vítima a fim de se beneficiar de uma. A igualdade das posições, ainda que sempre relativa, cria um sistema de dívidas e direitos que leva a enfatizar o que temos em comum mais do que aquilo que nos distingue e, nesse sentido, reforça a solidariedade. A igualdade de posições não aspira à comunidade perfeita das utopias e dos pesadelos comunistas, mas busca a qualidade da vida social e, por essa via, a autonomia pessoal, uma vez que eu sou tanto mais livre para agir quanto mais não sou ameaçado por desigualdades sociais demasiado grandes. Nesse aspecto, a concepção não contradiz a filosofia política liberal, ainda que leve a regular e limitar o livre jogo do liberalismo econômico. Resumindo, a maior igualdade possível é boa "em si mesma" na condição de não por em perigo a autonomia dos indivíduos e, mais ainda, ela é desejável porque reforça essa autonomia.

O segundo argumento a favor da igualdade de posições se baseia no fato de que ela é sem dúvida a melhor das maneiras de realizar a igualdade de oportunidades. Se as oportunidades são definidas como a possibilidade de circular na estrutura social, de ultrapassar as hierarquias, seja para ascender ou para baixar em função de seu mérito e de seu valor, parece ser evidente que essa fluidez aumenta ao se reduzir a distância entre as posições, que aqueles que ascendem não tenham demasiados obstáculos a ultrapassar e que aqueles que descem não arrisquem tudo perder. Ao contrário do que diz a lenda, há mais mobilidade social na França do que nos EUA, onde as distâncias entre distintas posições sociais são maiores. Com efeito, em seu 
princípio mesmo, o chamado à igualdade de oportunidades não diz nada das distâncias que separam as condições sociais, e essas podem ser tão grandes que os indivíduos podem não chegar nunca a atravessá-las - com exceção de alguns heróis dos quais se pergunta se não seriam a árvore da fluidez que esconde a floresta da imobilidade, ou, para dizer rapidamente, os heróis de pura propaganda. Apesar da sabedoria do que Rawls (1975) chama o "princípio da diferença” ${ }^{3}$ que requer que a igualdade de posições não leve a uma deterioração da condição dos menos favorecidos, é necessário constatar que, em todas as partes, as desigualdades se aprofundaram mais onde prevalecem as oportunidades do que onde prevalecem as posições.

A defesa da prioridade da igualdade de posições não deve ser confundida com a luta pela manutenção do Estado de bem-estar tal como é. Não supõe ignorar as críticas sérias que lhe dirigem todos os outsiders, todos aqueles que não podem se beneficiar desse Estado. A luta pela igualdade de posições exige, portanto, encarar sérias reformas no Estado de bem-estar e nos serviços públicos. Ela também supõe romper com algumas clientelas políticas tradicionais da esquerda que otimizam seus interesses nesse sistema, e exige rever o sistema de transferências sociais com o objetivo de saber, realmente, quem paga e quem ganha. Requer, em qualquer caso, acabar com o "véu da ignorância”. e eliminar ao menos em parte a opacidade que se tem gerado.

\section{Tradução: Antonio Augusto Gomes Batista}

\section{Notas técnicas: Vanda Mendes Ribeiro}

3 O "princípio da diferença" na teoria rawlsiana se reporta à necessidade de correção das desigualdades sociais nas sociedades democráticas contemporâneas que valorizam igualmente liberdade e igualdade. Nessas sociedades, para garantir o equilíbrio entre esses dois valores, gerando o que o autor nomeia de igualdade equitativa de oportunidades, certo nível de desigualdade social pode ser tolerado, desde que a dignidade que permite a cooperação social entre todos e as liberdades básicas sejam garantidas por meio de arranjos institucionais. [Nota técnica].

4 Rawls propõe a ideia de véu da ignorância como recurso lógico para enfrentar contradições na elaboração do seu modelo. Trata-se de um estado (a-histórico e hipotético) em que, para firmarem um contrato social, os indivíduos desconhecem a que posição social pertencem. Tendo interesses e sendo dotados do juízo reflexivo, seria razoável esperar que, sob o véu da ignorância, os indivíduos optem pela concepção política de justiça como equidade. Uma concepção que reconhece a necessidade de arranjos institucionais (ação do Estado) capazes de agir sobre as distribuições de bens de modo a preservar pilares da democracia contemporânea: a cooperação social e as liberdades básicas. [Nota técnica]. 


\section{The limits of equal opportunity}

François Dubet

Abstract: In recent decades, "equal opportunities" have been encroaching on another vision of socio-democratic system that the author calls "equal positions." Those that advocate for equal opportunities - the U.S. model - are less concerned with reducing inequalities than they are with fighting against discrimination that prevents movement through the social structure based on personal merit. The paper argues that the left should combine equal positions with equal opportunities, but by prioritizing the former, which should not be confused with a conservative defense of the Welfare State as we know it today.

Keywords: Equal opportunities. Equal positions. Meritocracy. Welfare State. 